\title{
Prognostic role of hypoxia-inducible factor-I alpha expression in osteosarcoma: a meta-analysis
}

This article was published in the following Dove Press journal:

OncoTargets and Therapy

14 March 2016

Number of times this article has been viewed

\author{
Hai-Yong Ren' \\ Yin-Hua Zhang ${ }^{1,2}$ \\ Heng-Yuan Li' \\ Tao Xie' \\ Ling-Ling Sun' \\ Ting Zhu' \\ Sheng-Dong Wang' \\ Zhao-Ming Ye' \\ 'Department of Orthopaedics, \\ Second Affiliated Hospital, College \\ of Medicine, Zhejiang University, \\ Hangzhou, ${ }^{2}$ The First Department \\ of Orthopaedics, Hospital of \\ Zhejiang General Corps of Armed \\ Police Forces, Jiaxing, People's \\ Republic of China
}

Correspondence: Zhao-Ming Ye Department of Orthopaedics, Second Affiliated Hospital, College of Medicine, Zhejiang University, No 88, Jiefang Road, Hangzhou 310009, People's Republic of China

Tel +86 57l 87783567

Fax +86 57I 87783688

Email yezhaomingzeyy@gmail.com
Background: Hypoxia-inducible factor- $1 \alpha$ (HIF-1 $\alpha$ ) plays an important role in tumor progression and metastasis. A number of studies have investigated the association of HIF-1 $\alpha$ with prognosis and clinicopathological characteristics of osteosarcoma but yielded inconsistent results.

Method: Systematic computerized searches were performed in PubMed, Embase, and Web of Science databases for relevant original articles. The pooled hazard ratios (HRs) and odds ratios (ORs) with corresponding confidence intervals (CIs) were calculated to assess the prognostic value of HIF-1 $\alpha$ expression. The standard mean difference was used to analyze the continuous variable.

Results: Finally, nine studies comprising 486 patients were subjected to final analysis. Protein expression level of HIF- $1 \alpha$ was found to be significantly related to overall survival (HR =3.0; 95\% CI: 1.46-6.15), disease-free survival (HR =2.23; 95\% CI: 1.26-3.92), pathologic grade $(\mathrm{OR}=21.33$; 95\% CI: 4.60-98.88), tumor stage (OR $=10.29 ; 95 \%$ CI: 3.55-29.82), chemotherapy response ( $\mathrm{OR}=9.68 ; 95 \% \mathrm{CI}: 1.87-50.18)$, metastasis ( $\mathrm{OR}=5.06 ; 95 \% \mathrm{CI}: 2.87-8.92)$, and microvessel density ( standard mean difference $=2.83$; 95\% CI: 2.28-3.39).

Conclusion: This meta-analysis revealed that overexpression of HIF- $1 \alpha$ is a predictive factor of poor outcomes for osteosarcoma. HIF-1 $\alpha$ appeared to play an important role in prognostic evaluation and may be a potential target in antitumoral therapy.

Keywords: HIF-1 $\alpha$, osteosarcoma, prognosis, meta-analysis

\section{Introduction}

Osteosarcoma is the most common primary bone tumor in children and young adults. ${ }^{1}$ The incidence of osteosarcoma in the general population is two to three cases per million per year, but in adolescence, the annual incidence is higher and peaks at eight to eleven cases per million per year at 15-19 years of age. ${ }^{2}$ It is characterized by the proliferation of malignant mesenchymal cells that form osteoid bone., ${ }^{3,4}$ The tumor occurs predominantly in the metaphysis (the sites of bone growth), presumably because proliferation makes the osteoblastic cells in this region acquire mutations that could lead to cell transformation. ${ }^{5,6}$ In all, $10 \%-15 \%$ of patients with newly diagnosed osteosarcoma have detectable metastases at diagnosis, of which $>90 \%$ occur in the lungs. ${ }^{7,8}$ Treatment of the disease was mainly limb amputation, and the survival rate was $10 \%-20 \%$ before 1970 s when chemotherapy was not included as part of therapeutic protocols..$^{5,9}$ With the introduction of multidrug chemotherapy and advanced surgery, the 5-year survival rate has significantly improved to $60 \%-80 \%{ }^{10-13}$ However, the treatment of osteosarcoma is still unsatisfactory for the risk of local relapse and the development of metastasis. ${ }^{12,14}$ For these patients, they have $<20 \%$ chance of long-term survival, despite aggressive therapies that have 
largely unchanged during the past 30 years. ${ }^{15}$ To improve the clinical outcomes for patients with poor prognosis, it is crucial to identify novel biomarkers for prognostic assessment and therapeutic targets to osteosarcoma.

Hypoxia is a key element that plays a critical role in the development and progression of tumors. ${ }^{16,17}$ Hypoxiainducible factor-1 (HIF-1), a major transcription factor that mediates adaptive responses to low oxygen tension, is a heterodimeric protein consisting of the following two subunits: HIF- $1 \alpha$ and HIF- $1 \beta .{ }^{18}$ HIF- $1 \beta$ is constitutively expressed, while HIF- $1 \alpha$ is regulated by oxygen levels that determine HIF-1 activity. ${ }^{19,20}$ HIF- $1 \alpha$ is a hallmark of tumor hypoxia, which is widely expressed in solid tumors. The HIF-1 $\alpha$ expression has been noted in many different types of malignancies, including carcinoma of lung, ${ }^{21}$ pancreas, ${ }^{22}$ liver, ${ }^{23}$ breast, ${ }^{24}$ esophagus, ${ }^{25}$ colon, ${ }^{26}$ and ovary, ${ }^{27}$ and has been associated with adverse clinical outcomes. HIF- $1 \alpha$ is also reported to be related to poor prognosis in osteosarcoma, but the results of the existing literature are inconsistent or even conflicting. ${ }^{28-36}$ Therefore, we conducted a meta-analysis of these studies to evaluate the relation of HIF-1 $\alpha$ protein expression with clinicopathological factors and prognosis of osteosarcoma.

\section{Methods}

\section{Search strategy and selection criteria}

The electronic databases of PubMed, Embase, and Web of Science were searched for studies that investigated the prognostic significance of HIF- $1 \alpha$ in osteosarcoma to be included in the present meta-analysis. The search ended on August 1, 2015, and no lower date limit was applied. The search terms used were as follows: "osteosarcoma" or "bone sarcoma" or "osteogenic sarcoma" and "HIF-1 $\alpha$ " or "HIF-1 alpha" or "hypoxia-inducible factor-1 $\alpha$ " or "hypoxia-inducible factor-1 alpha". A comprehensive search of reference lists of all review articles and selected papers was performed to identify additional reports.

Two independent reviewers (H-Y Ren and T Xie) assessed the eligibility of studies by reviewing titles and abstracts identified by the search. Differences were resolved by discussion with a third author (H-Y Li). The inclusion criteria for primary studies were as follows: 1 ) HIF-1 $\alpha$ expression evaluated in the primary osteosarcoma tissues; 2) HIF-1 $\alpha$ expression detected by IHC (immunohistochemistry); 3 ) relationship demonstrated between HIF-1 $\alpha$ expression and osteosarcoma clinicopathological parameters or prognosis; and 4) articles published as a full paper in English. The exclusion criteria were as follows: 1) duplicate studies on the same patients; 2) studies written in non-English; 3) case reports, editorials, letters, reviews, abstracts, animal, or cell studies; 4) not possible to extract the required data.

\section{Data extraction and study assessment}

Two investigators (H-Y Ren and $\mathrm{T} \mathrm{Xie}$ ) independently extracted data from eligible studies, disagreements were resolved by discussion with a third author (H-Y Li). The following information was extracted: name of first author, year of publication, country, sample size, age, sex, pathologic grade, tumor stage, metastasis, tumor size, chemotherapy response, tumor site, histological type, microvessel density (MVD), and hazard ratio (HR) estimation. Methodological quality of the included studies was assessed with the Newcastle-Ottawa scale. ${ }^{37}$

\section{Statistical analysis}

For each study with assessment of overall survival (OS) or disease-free survival (DFS), the HRs and corresponding 95\% confidence intervals (CIs) were extracted if the author had provided the data. Otherwise, these data were calculated according to the methods described by Parmar et al..$^{38}$ Odds ratios (ORs) were estimated for clinicopathological variables (age, $>20$ vs $\leq 20$ years old; sex, male vs female; tumor stages, high vs low; metastasis, yes vs no; chemotherapy response, poor vs good; tumor size, large vs small; tumor site at tibia or femur vs elsewhere; and histopathology, osteoblastic type vs other types). Continuous variables were analyzed by the standard mean difference (SMD). Heterogeneity among studies was measured by $Q$-test and $P^{2}$-test ( $P$-value $<0.10$ was considered statistically significant for heterogeneity). ${ }^{39,40}$ The fixed effects model was used to combine the individual HR or OR estimates when no significant heterogeneity was identified among studies, otherwise, the random effects model was used. ${ }^{41}$ Statistical significance was defined as a $P$-value $<0.05$. Publication bias and sensitivity analysis were not assessed for the primary outcome because limited studies were included in each analysis. All statistical analyses were conducted using software from the Cochrane Collaboration (RevMan Version 5.0; Nordic Cochrane Centre, Copenhagen, Denmark).

\section{Results \\ Study selection}

We initially retrieved 263 unique citations from PubMed, Embase, and Web of Science after excluding duplicates until August 1, 2015. Of these, the majority were excluded after the first screening based on abstracts or titles because 
they were reviews, case reports, letters, editorial articles, or not relevant to the protein expression of HIF-1 $\alpha$ in osteosarcoma. After examining the remaining eleven articles, one was excluded due to insufficient data to be extracted, ${ }^{42}$ and one was excluded as it was the protein HIF-1 rather than HIF- $1 \alpha$ analyzed in the study. ${ }^{43}$ Finally, nine studies were included in this meta-analysis. ${ }^{28-36}$ Figure 1 shows the process of the study selection. The main characteristics of the eligible studies are shown in Table 1 . The list of records identified by database searching and the studies included in the meta-analysis are provided in the Supplementary materials.

\section{Association of HIF- I $\alpha$ protein expression with survival outcomes}

Four studies were included to analyse the association of HIF-1 $\alpha$ expression with survival..$^{28,31,32,36}$ Two studies reported the association on OS and three on DFS. When these studies were summarized quantificationally, we found that the pooled HR on OS was 3.0 (95\% CI: 1.46-6.15) with no heterogeneity $\left(I^{2}=0 \%, P=0.48\right)$ (Figure 2A) and HR on DFS was 2.23 (95\% CI: 1.26-3.92) with no heterogeneity $\left(I^{2}=0 \%, P=0.45\right)$ (Figure $\left.2 \mathrm{~B}\right)$. The results indicate that HIF-1 $\alpha$ expression is associated with a poor prognosis in osteosarcoma.

\section{Association of HIF-I $\alpha$ protein expression with clinicopathological factors}

Based on the available data in the included studies, we analyzed the relationship of HIF-1 $\alpha$ expression with nine clinicopathological factors of osteosarcoma (Table 2). ${ }^{28-35}$ Of these, four factors were found to be significantly related to HIF- $1 \alpha$ expression: ORs were 21.33 (95\% CI: 4.60-98.88) for pathologic grade (high vs low) (Figure 3A), 10.29 (95\% CI: 3.55-29.82) for tumor stage (high vs low) (Figure 3B), 9.68 (95\% CI: 1.87-50.18) for chemotherapy response (poor vs good) (Figure 3C), and 5.06 (95\% CI: 2.87-8.92) for metastasis (yes vs no) (Figure 3D), respectively. However, no statistically significant relationship with HIF- $1 \alpha$ expression was found

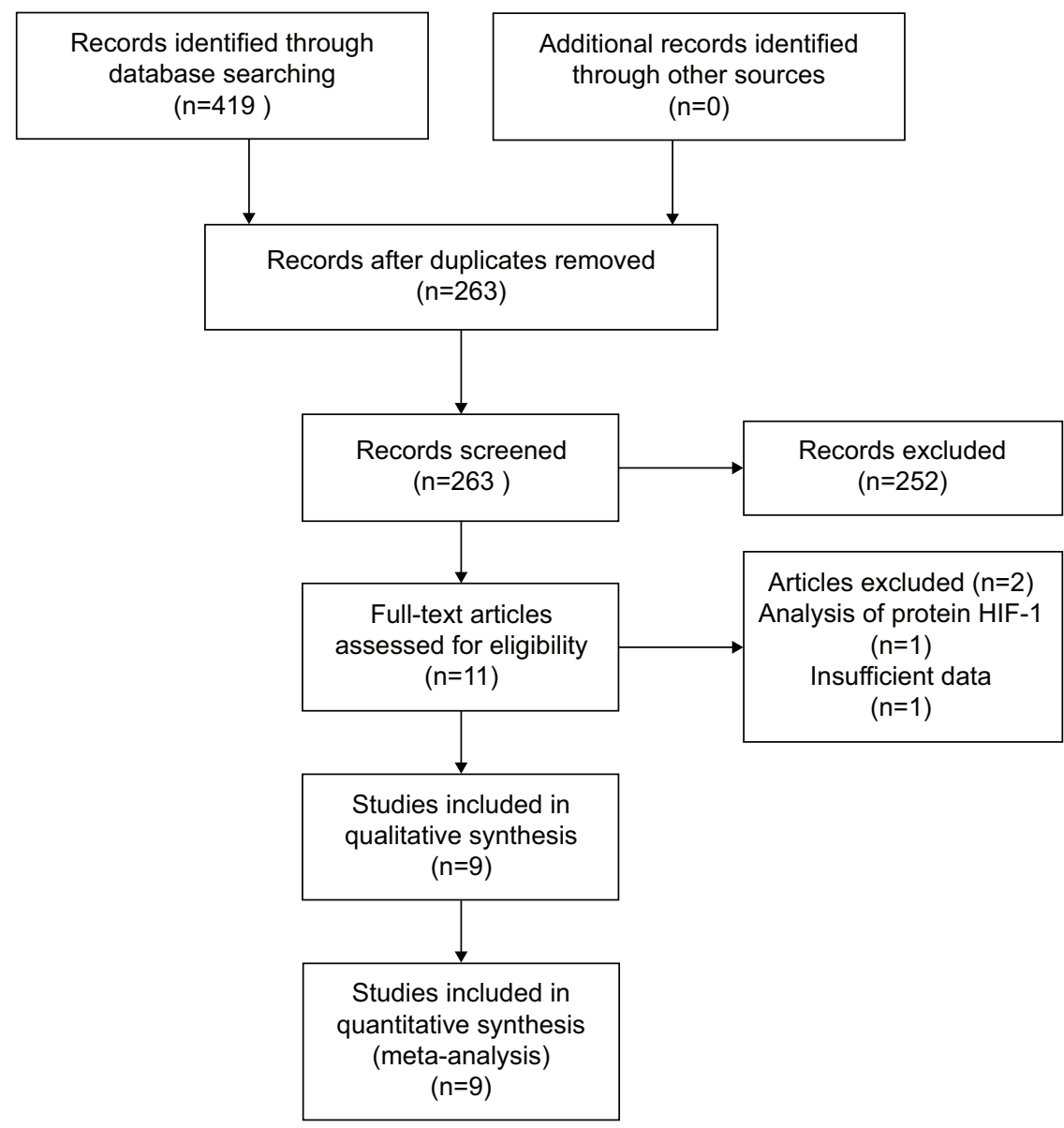

Figure I Flow chart of study selection. 


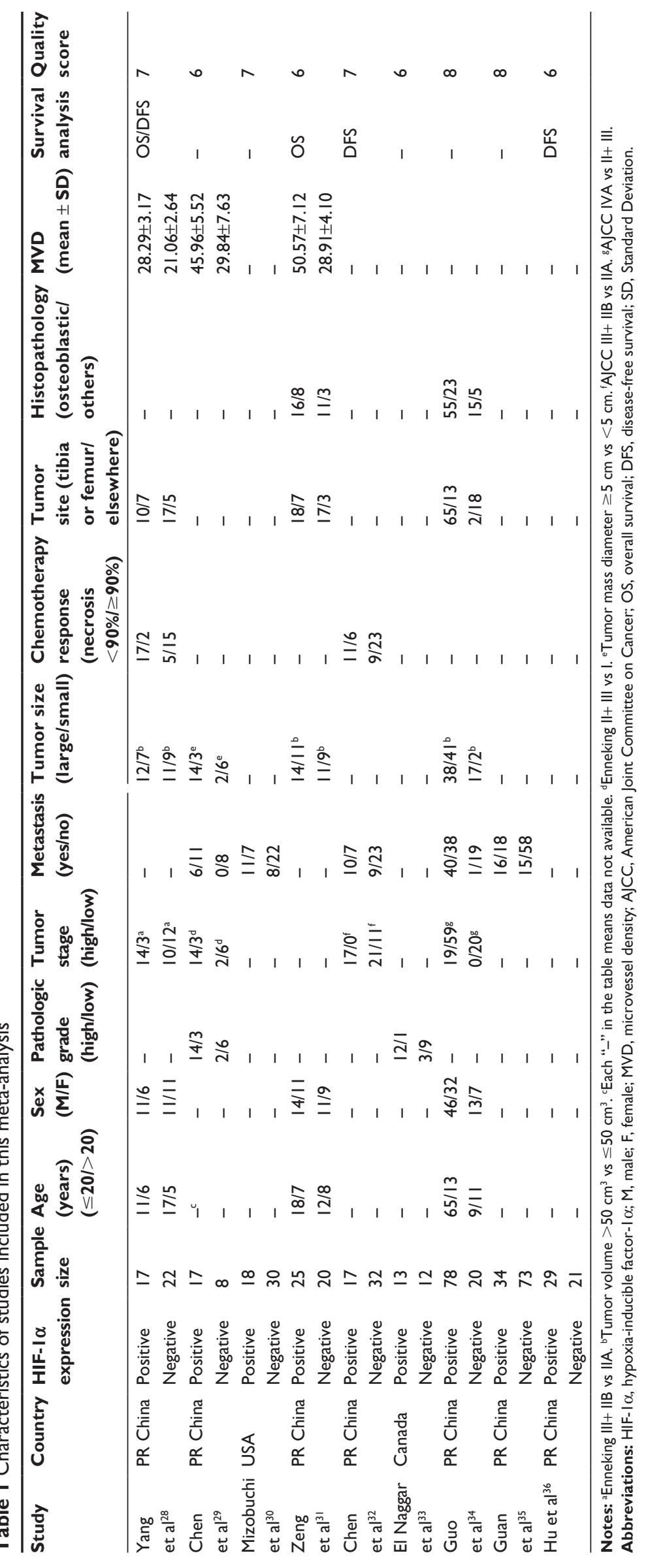




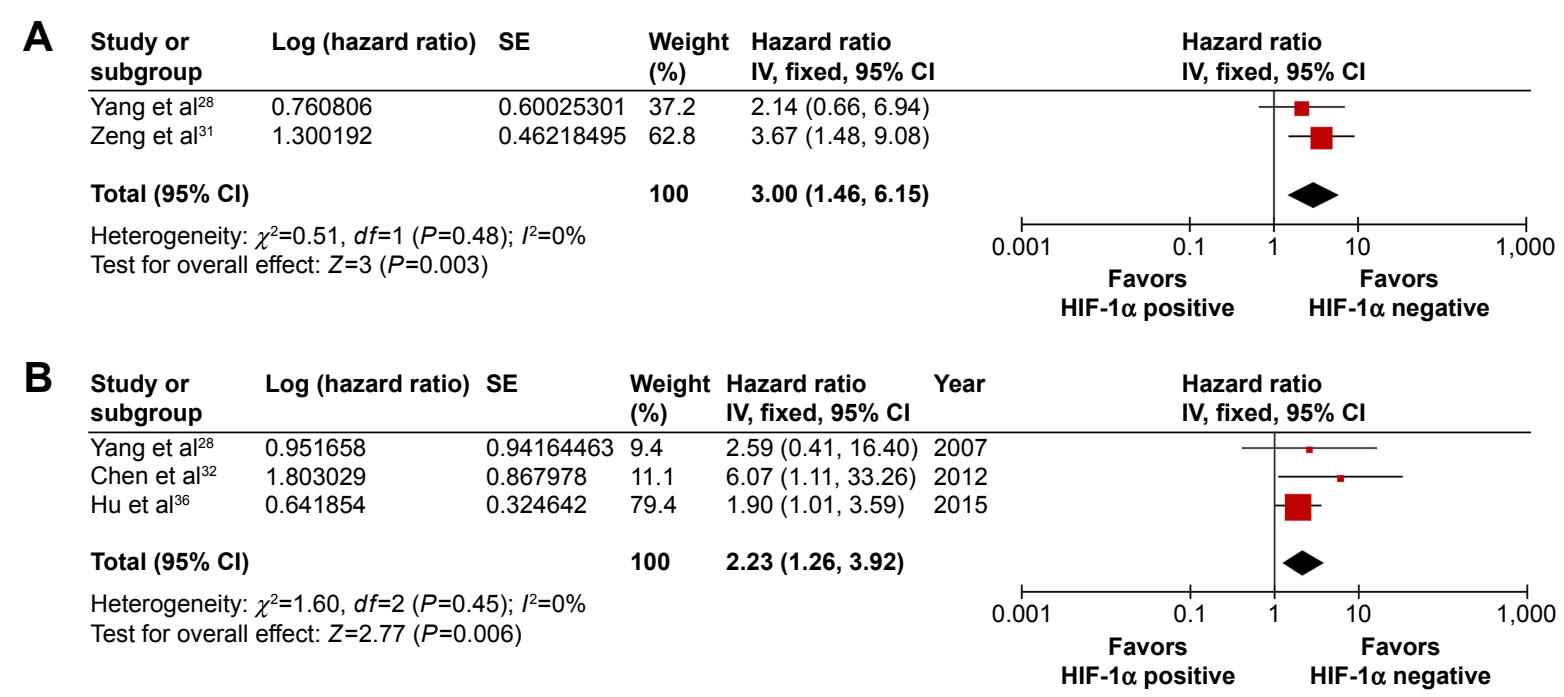

Figure 2 Forest plots of associations between HIF- I $\alpha$ expression and survival.

Notes: (A) Overall survival (OS). (B) Disease-free survival (DFS).

Abbreviations: SE, standard error; IV, inverse variance; $\mathrm{Cl}$, confidence interval; HIF-I $\alpha$, hypoxia-inducible factor-I $\alpha$.

among other five factors: ORs were 0.66 (95\% CI: $0.15-$ 2.87 ) for age ( $\leq 20$ years vs $>20$ years) (Figure $4 \mathrm{~A}), 0.88$ (95\% CI: 0.44-1.74) for sex (male vs female) (Figure 4B), 1.12 (95\% CI: 0.22-5.76) for tumor size (large vs small) (Figure 4C), 2.02 (95\% CI: 0.10-39.71) for tumor site (tibia or femur vs other sites) (Figure 4D), and 0.70 (95\% CI: 0.28-1.73) for histopathology (osteoblastic vs other types) (Figure 4E).

\section{Association of HIF-I $\alpha$ protein expression with MVD}

Three studies with 109 patients investigated the relationship between HIF-1 $\alpha$ expression and MVD. ${ }^{28,29,31}$ The HIF- $1 \alpha-$ positive expression group showed a significantly greater number of vessels than the HIF-1 $\alpha$-negative group $(\mathrm{SMD}=2.83,95 \% \mathrm{CI}: 2.28-3.39, P<0.00001)$. A fixed effects model was used because no heterogeneity was noted $\left(P=0.2, I^{2}=38 \%\right)$ (Figure 5$)$. It is demonstrated that overexpression of HIF-1 $\alpha$ was significantly correlated with greater MVD.

\section{Discussion}

In solid tumors, cells are commonly in a hypoxic state. ${ }^{20}$ The most important mediator identified to date of the cell's response to hypoxia is the HIF-1 transcription factor. ${ }^{44}$ The activity of HIF-1 in tumors depends on the availability of the HIF-1 $\alpha$ subunit, the levels of which increase under intratumoral hypoxic conditions and through the activation of oncogenes and/or inactivation of tumor suppressor genes. ${ }^{45} \mathrm{HIF}-1 \alpha$ forms a heterodimer with HIF-1 $\beta$. The dimer binds to highly conserved hypoxia-response elements in the promoter of target genes and activates their expressions to mediate acute and chronic adaptation to oxygen deficiency, including erythropoiesis, glycolysis, angiogenesis, inhibition of apoptosis, inhibition of cell differentiation, and promotion of cell invasion. ${ }^{17,46}$

Osteosarcoma is a solid malignant tumor characterized by rapid growth and a high rate of metastasis. ${ }^{5}$ The hypoxic microenvironment that accompanies growth of the tumor mass would leads to increased expression of HIF-1 $\alpha$. A number of studies have investigated the role of HIF-1 $\alpha$ expression in patients with osteosarcoma but have yielded inconsistent and inconclusive results. Therefore, we performed a meta-analysis of the published studies to derive an overall pooled estimation of the relationship between HIF-1 $\alpha$ expression and prognosis. This study summarized nine articles, including 486 cases, and showed that overexpression of HIF- $1 \alpha$ was associated with lower survival rate, higher MVD, metastasis, higher pathologic grade, tumor stage, and poor chemotherapy response in osteosarcoma.

Among the included studies, positive expression rate of HIF- $1 \alpha$ had been reported in $31.78 \%-79.59 \%$ of osteosarcoma patients with mean rate of $52.0 \%$. In agreement with other cancers, overexpression of HIF-1 $\alpha$ in osteosarcoma correlates with vascular endothelial growth factor and apurinic/apyrimidinic endonuclease 1 expressions, which are responsible for angiogenesis. ${ }^{32}$ These results exhibited that significantly higher MVD appeared in the tumor tissue. Greater new blood vessels would increase tumor oxygenation, accelerate tumor growth as well as promote tumor invasion and migration to regional or distant sites, resulting in metastasis and higher 


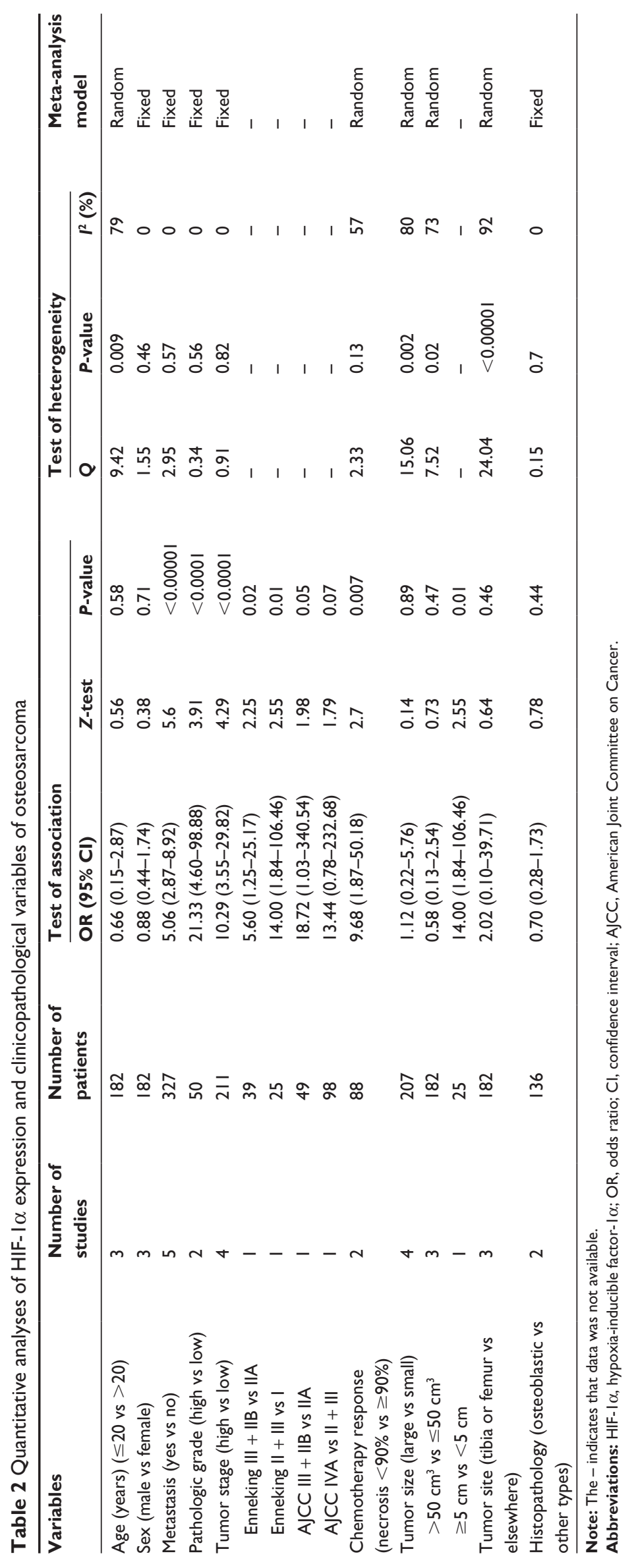




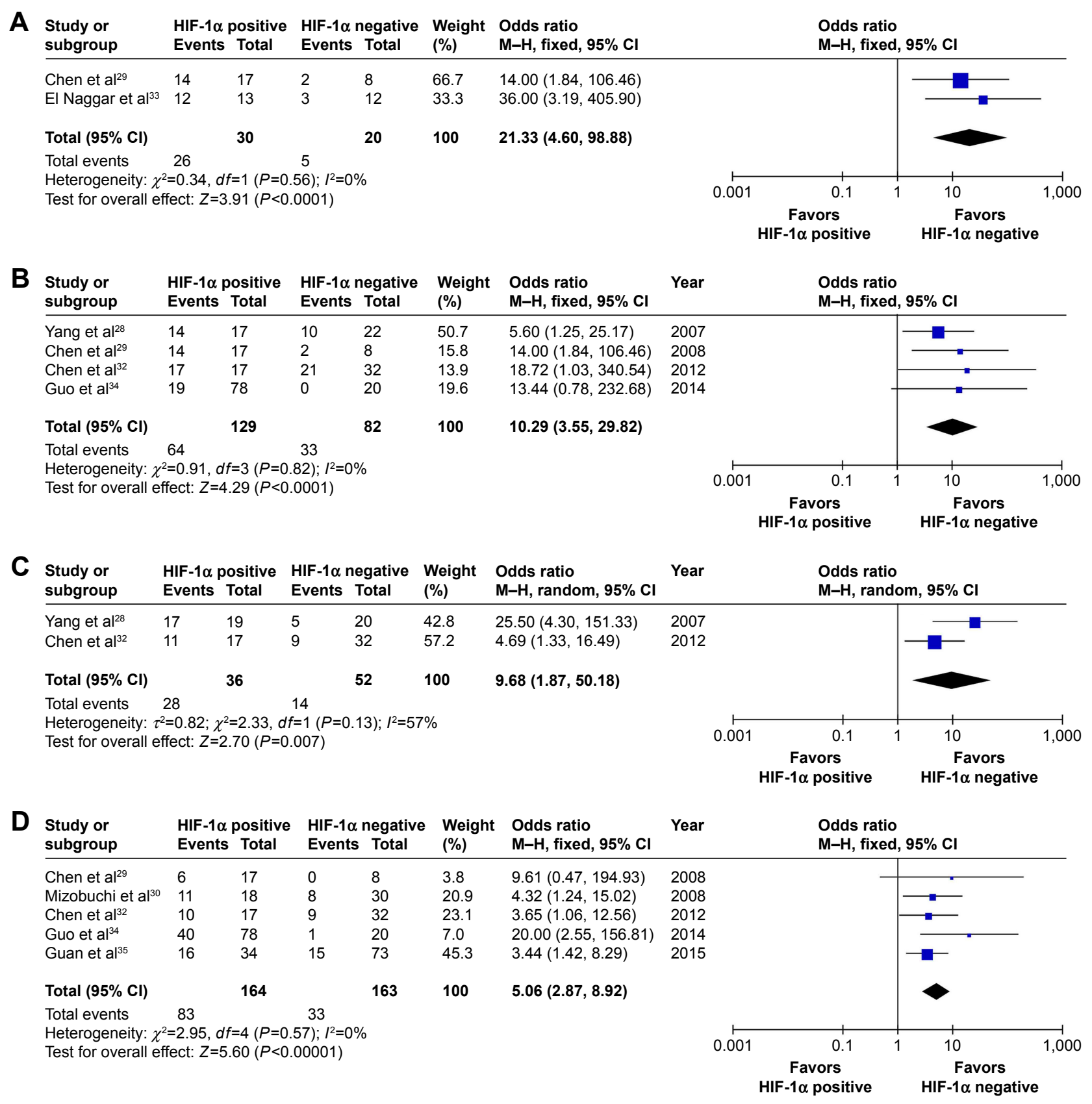

Figure 3 Significant associations were revealed between HIF-I $\alpha$ expression and clinicopathological factors of histological grade (A), tumor stage (B), chemotherapy response $(\mathbf{C})$, and metastasis $(\mathbf{D})$.

Abbreviations: HIF-I $\alpha$, hypoxia-inducible factor- $\mathrm{I} \alpha \mathrm{M}-\mathrm{H}$, Mantel-Haenszel; $\mathrm{Cl}$, confidence interval.

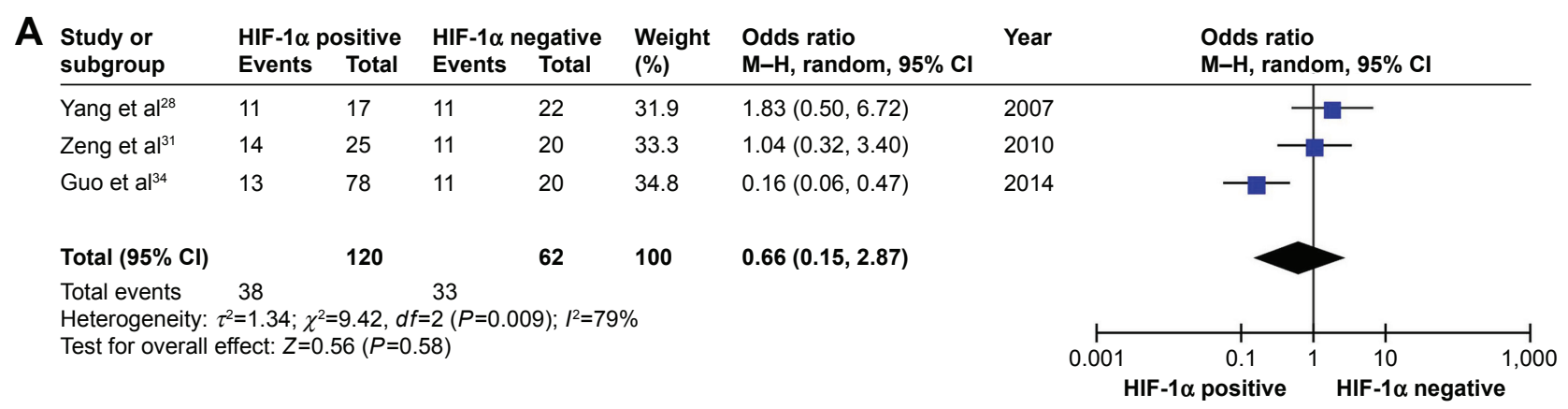

Figure 4 (Continued) 


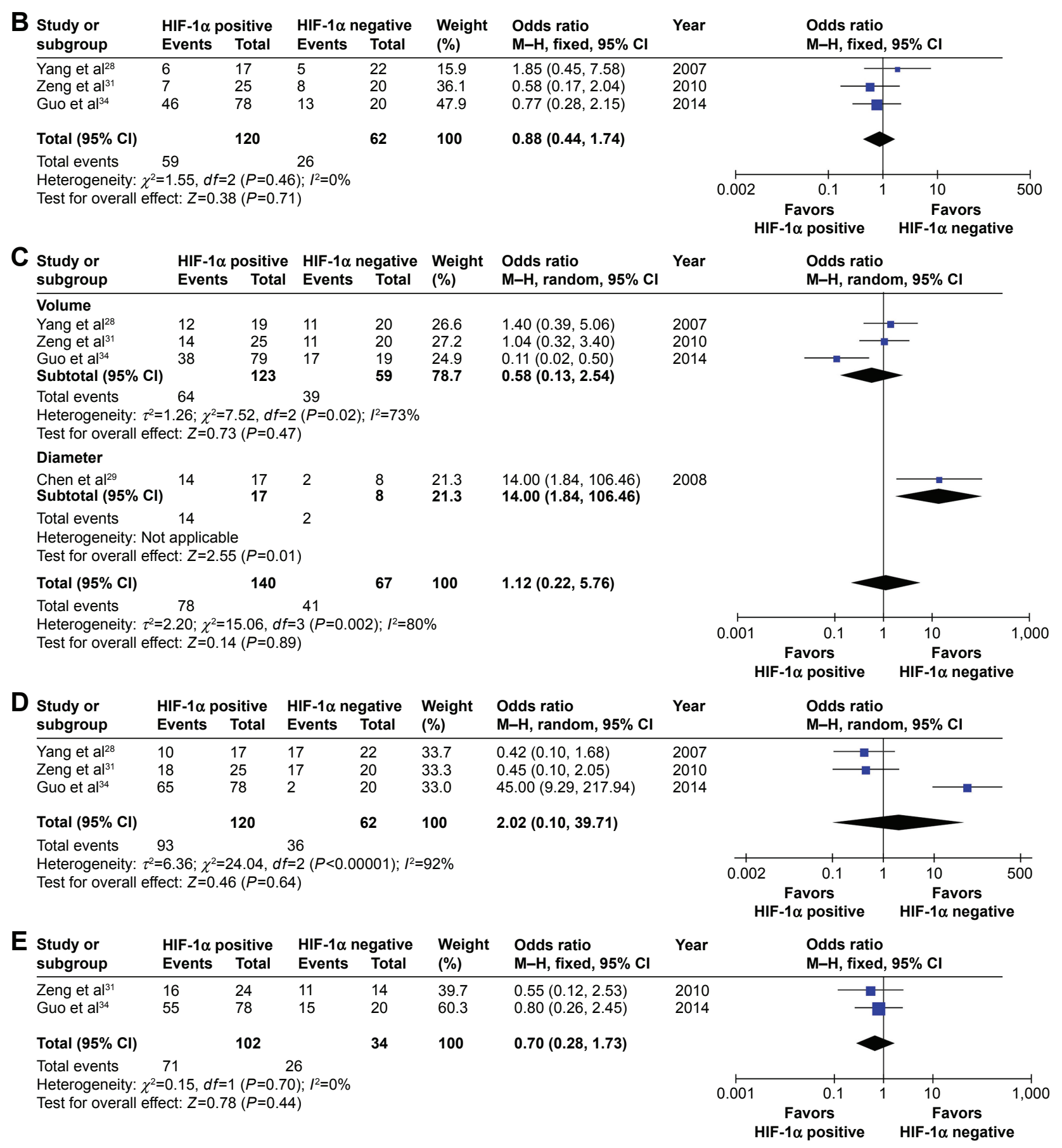

Figure 4 No significant associations were found between HIF-I $\alpha$ expression and clinicopathological factors of age (A), sex (B), tumor size (C), tumor site (D), and histopathology (E).

Abbreviations: HIF-I $\alpha$, hypoxia-inducible factor-I $\alpha$; M-H, Mantel-Haenszel; Cl, confidence interval.

cancer stage. In addition, the results showed that HIF- $1 \alpha$ expression was significantly correlated with advanced grade of osteosarcoma. Treatment failure is commonly due to the development of chemoresistance. Results of this analysis revealed that overexpression of HIF- $1 \alpha$ is significantly related to poor chemotherapy response, which was an important prognostic factor for osteosarcoma. Roncuzzi et a ${ }^{47}$ reported that multidrug resistance phenotype of osteosarcoma was also mediated by HIF-1 $\alpha$. It was suggested that HIF-1 $\alpha$ promoted the outward transport of intracellular doxorubicin by activating the P-glycoprotein expression and hindered apoptosis by regulating the expression of c-Myc and $\mathrm{p} 21$. Correlations of HIF- $1 \alpha$ expression with prognostic factors for CXC chemokine receptor 4, cyclooxygenase 2, 


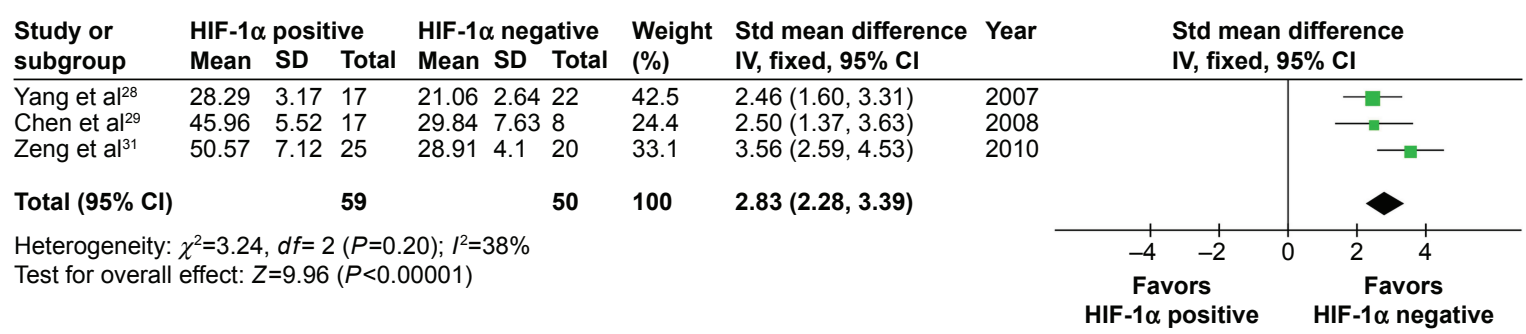

Figure 5 Forest plot of association between HIF-I $\alpha$ expression and microvessel density (MVD).

Abbreviations: HIF-I $\alpha$, hypoxia-inducible factor- $\mathrm{I} \alpha$; IV, inverse variance; $\mathrm{Cl}$, confidence interval; SD, standard deviation.

heparanase, and differentiated embryonic chondrocyte gene 2 were also reported in osteosarcoma. ${ }^{31,32,34,36}$ Apparent pooled lower OS and DFS rates were found in patients with HIF-1 $\alpha$ overexpression, indicating poor prognostic value of HIF- $1 \alpha$ expression in osteosarcoma. It is reasonable to infer that hypoxia would be more evident when tumor size gets larger, and then higher level of HIF-1 $\alpha$ could be tested. However, with apparent heterogeneity, no significant correlation was found between HIF- $1 \alpha$ and tumor size in this study. More studies are needed to further explore this relation. No significant correlation of HIF- $1 \alpha$ expression with clinical variables of age, sex, tumor site, and histopathology of osteosarcoma appeared in this study.

Meanwhile, there were several limitations in this metaanalysis. First, most of the included studies were conducted in the People's Republic of China. The reason may be that Chinese scientists attach more importance to improving the clinical outcomes for osteosarcoma patients. We included only studies that were published in English, studies unpublished or in other languages that meet the inclusion criteria may be missed. A tendency for journals to publish positive findings over negative results may also lead to an overestimation of the prognostic value. Second, the approach of extrapolating the HRs could introduce potential source of bias. When not reported in original articles, HRs were extrapolated from the survival curves or calculated from the provided data in the eligible studies according to the method of Parmar et al. ${ }^{38}$ The HR information obtained by statistical software unavoidably developed a decrease in accuracy. Third, significant heterogeneity was found across the selected studies when investigating the relationship of HIF-1 $\alpha$ expression with age, chemotherapy response, tumor size, and tumor site. More well-designed clinical studies with large cases of osteosarcoma should be performed to derive more accurate results. Tumor stages were evaluated by different systems and grouped with variant cutoffs among the included studies, which would make the results less reliable. Finally, assessment of the expression of HIF- $1 \alpha$ in the included studies was inconsistent. Differences in primary antibodies with varying dilutions, staining protocols, evaluation standards, and cutoff values for high HIF-1 $\alpha$ expression may contribute to heterogeneity.

\section{Conclusion}

In conclusion, the systematic review of the literatures shows that high expression of HIF-1 $\alpha$ in patients with osteosarcoma predicts low survival rate and poor clinicopathological characteristics. High HIF-1 $\alpha$ levels might be a valuable prognostic factor for osteosarcoma patients and predict high cancer stage, metastasis, and chemoresistance. To become a clinically useful prognostic marker for individual patients or a valid cancer drug target, these results need to be clearly confirmed by large, well-designed prospective study with appropriate multivariate analyses.

\section{Acknowledgment}

This work was supported by National Natural Science Foundation of China (grant numbers 81172547 and 30973444).

\section{Disclosure}

The authors report no conflicts of interest in this work.

\section{References}

1. Picci P. Osteosarcoma (osteogenic sarcoma). Orphanet J Rare Dis. 2007; $2: 6$

2. Ritter J, Bielack SS. Osteosarcoma. Ann Oncol. 2010;21(suppl 7): vii320-vii325.

3. Sissons HA. The WHO classification of bone tumors. Recent Results Cancer Res. 1976;54:104-108.

4. Fox MG, Trotta BM. Osteosarcoma: review of the various types with emphasis on recent advancements in imaging. Semin Musculoskelet Radiol. 2013;17(2):123-136.

5. Ta HT, Dass CR, Choong PF, Dunstan DE. Osteosarcoma treatment: state of the art. Cancer Metastasis Rev. 2009;28(1-2):247-263.

6. Futani H, Minamizaki T, Nishimoto Y, Abe S, Yabe H, Ueda T. Longterm follow-up after limb salvage in skeletally immature children with a primary malignant tumor of the distal end of the femur. $J$ Bone Joint Surg Am. 2006;88(3):595-603.

7. Bielack SS, Kempf-Bielack B, Delling G, et al. Prognostic factors in high-grade osteosarcoma of the extremities or trunk: an analysis of 1,702 patients treated on neoadjuvant cooperative osteosarcoma study group protocols. J Clin Oncol. 2002;20(3):776-790. 
8. Chou AJ, Kleinerman ES, Krailo MD, et al; Children's Oncology Group. Addition of muramyl tripeptide to chemotherapy for patients with newly diagnosed metastatic osteosarcoma: a report from the Children's Oncology Group. Cancer. 2009;115(22):5339-5348.

9. Arndt CA, Crist WM. Common musculoskeletal tumors of childhood and adolescence. $N$ Engl J Med. 1999;341(5):342-352.

10. Bacci G, Bertoni F, Longhi A, et al. Neoadjuvant chemotherapy for high-grade central osteosarcoma of the extremity. Histologic response to preoperative chemotherapy correlates with histologic subtype of the tumor. Cancer. 2003;97(12):3068-3075.

11. Goorin AM, Schwartzentruber DJ, Devidas M, et al; Pediatric Oncology Group. Presurgical chemotherapy compared with immediate surgery and adjuvant chemotherapy for nonmetastatic osteosarcoma: Pediatric Oncology Group Study POG-8651. J Clin Oncol. 2003;21(8): $1574-1580$.

12. Hameed M, Dorfman H. Primary malignant bone tumors - recent developments. Semin Diagn Pathol. 2011;28(1):86-101.

13. Meyers PA, Schwartz CL, Krailo M, et al. Osteosarcoma: a randomized, prospective trial of the addition of ifosfamide and/or muramyl tripeptide to cisplatin, doxorubicin, and high-dose methotrexate. J Clin Oncol.2005; 23(9):2004-2011.

14. Mirabello L, Troisi RJ, Savage SA. Osteosarcoma incidence and survival rates from 1973 to 2004: data from the Surveillance, Epidemiology, and End Results Program. Cancer. 2009;115(7):1531-1543.

15. Chou AJ, Geller DS, Gorlick R. Therapy for osteosarcoma: where do we go from here? Paediatr Drugs. 2008;10(5):315-327.

16. Dachs GU, Patterson AV, Firth JD, et al. Targeting gene expression to hypoxic tumor cells. Nat Med. 1997;3(5):515-520.

17. Powis G, Kirkpatrick L. Hypoxia inducible factor-1alpha as a cancer drug target. Cancer Ther. 2004;3(5):647-654.

18. Wang GL, Jiang BH, Rue EA, Semenza GL. Hypoxia-inducible factor 1 is a basic-helix-loop-helix-PAS heterodimer regulated by cellular $\mathrm{O} 2$ tension. Proc Natl Acad Sci U S A. 1995;92(12):5510-5514.

19. Huang LE, Arany Z, Livingston DM, Bunn HF. Activation of hypoxia-inducible transcription factor depends primarily upon redox-sensitive stabilization of its alpha subunit. J Biol Chem. 1996;271(50):32253-32259.

20. Richard DE, Berra E, Pouyssegur J. Angiogenesis: how a tumor adapts to hypoxia. Biochem Biophys Res Commun. 1999;266(3):718-722.

21. Wang Q, Hu DF, Rui Y, Jiang AB, Liu ZL, Huang LN. Prognosis value of HIF-1alpha expression in patients with non-small cell lung cancer. Gene. 2014;541(2):69-74.

22. Ye LY, Zhang Q, Bai XL, Pankaj P, Hu QD, Liang TB. Hypoxia-inducible factor 1alpha expression and its clinical significance in pancreatic cancer: a meta-analysis. Pancreatology. 2014;14(5):391-397.

23. Cao S, Yang S, Wu C, Wang Y, Jiang J, LuZ. Protein expression of hypoxiainducible factor-1 alpha and hepatocellular carcinoma: a systematic review with meta-analysis. Clin Res Hepatol Gastroenterol. 2014; 38(5):598-603.

24. Sun G, Wang Y, Hu W. Correlation between HIF-1alpha expression and breast cancer risk: a meta-analysis. Breast J. 2014;20(2):213-215.

25. Ping W, Sun W, Zu Y, Chen W, Fu X. Clinicopathological and prognostic significance of hypoxia-inducible factor-1alpha in esophageal squamous cell carcinoma: a meta-analysis. Tumour Biol. 2014;35(5):4401-4409.

26. Chen Z, He X, Xia W, et al. Prognostic value and clinicopathological differences of HIFs in colorectal cancer: evidence from meta-analysis. PLoS One. 2013;8(12):e80337.

27. Jin $Y$, Wang H, Liang X, Ma J, Wang Y. Pathological and prognostic significance of hypoxia-inducible factor 1alpha expression in epithelial ovarian cancer: a meta-analysis. Tumour Biol. 2014;35(8):8149-8159.
28. Yang QC, Zeng BF, Dong Y, Shi ZM, Jiang ZM, Huang J. Overexpression of hypoxia-inducible factor-1alpha in human osteosarcoma: correlation with clinicopathological parameters and survival outcome. Jpn J Clin Oncol. 2007;37(2):127-134.

29. Chen WL, Feng HJ, Li HG. Expression and significance of hypoxemiainducible factor-1alpha in osteosarcoma of the jaws. Oral Surg Oral Med Oral Pathol Oral Radiol Endod. 2008;106(2):254-257.

30. Mizobuchi H, Garcia-Castellano JM, Philip S, Healey JH, Gorlick R. Hypoxia markers in human osteosarcoma: an exploratory study. Clin Orthop Relat Res. 2008;466(9):2052-2059.

31. Zeng C, Ke Z, Luo C, Yang Z, Wang L. Heparanase participates in the growth and invasion of human U-2OS osteosarcoma cells and its close relationship with hypoxia-inducible factor- $1 \alpha$ in osteosarcoma. Neoplasma. 2010;57(6):562-571.

32. Chen Y, Yang Y, Yuan Z, Wang C, Shi Y. Predicting chemosensitivity in osteosarcoma prior to chemotherapy: an investigational study of biomarkers with immunohistochemistry. Oncol Lett. 2012;3(5):1011-1016.

33. El Naggar A, Clarkson P, Zhang F, Mathers J, Tognon C, Sorensen PH. Expression and stability of hypoxia inducible factor 1alpha in osteosarcoma. Pediatr Blood Cancer. 2012;59(7):1215-1222.

34. Guo M, Cai C, Zhao G, et al. Hypoxia promotes migration and induces CXCR4 expression via HIF-1alpha activation in human osteosarcoma. PLoS One. 2014;9(3):e90518.

35. Guan G, Zhang Y, Lu Y, et al. The HIF-1alpha/CXCR4 pathway supports hypoxia-induced metastasis of human osteosarcoma cells. Cancer Lett. 2015;357(1):254-264.

36. Hu T, He N, Yang Y, Yin C, Sang N, Yang Q. DEC2 expression is positively correlated with HIF-1 activation and the invasiveness of human osteosarcomas. J Exp Clin Cancer Res. 2015;34:22.

37. Stang A. Critical evaluation of the Newcastle-Ottawa scale for the assessment of the quality of nonrandomized studies in meta-analyses. Eur J Epidemiol. 2010;25(9):603-605.

38. Parmar MK, Torri V, Stewart L. Extracting summary statistics to perform meta-analyses of the published literature for survival endpoints. Stat Med. 1998;17(24):2815-2834.

39. DerSimonian R. Meta-analysis in the design and monitoring of clinical trials. Stat Med. 1996;15(12):1237-1248; discussion 1249-1252.

40. Higgins JP, Thompson SG, Deeks JJ, Altman DG. Measuring inconsistency in meta-analyses. BMJ. 2003;327(7414):557-560.

41. Bax L, Ikeda N, Fukui N, Yaju Y, Tsuruta H, Moons KG. More than numbers: the power of graphs in meta-analysis. Am J Epidemiol. 2009; 169(2):249-255.

42. Yang QC, Zeng BF, Shi ZM, et al. Inhibition of hypoxia-induced angiogenesis by trichostatin A via suppression of HIF-la activity in human osteosarcoma. J Exp Clin Cancer Res. 2006;25(4):593-599.

43. Zhao H, Wu Y, Chen Y, Liu H. Clinical significance of hypoxiainducible factor 1 and VEGF-A in osteosarcoma. Int J Clin Oncol. 2015; 20(6): 1233-1243.

44. Harris AL. Hypoxia - a key regulatory factor in tumour growth. Nat Rev Cancer. 2002;2(1):38-47.

45. Semenza GL. Targeting HIF-1 for cancer therapy. Nat Rev Cancer. 2003; 3(10):721-732.

46. Zimna A, Kurpisz M. Hypoxia-inducible factor-1 in physiological and pathophysiological angiogenesis: applications and therapies. Biomed Res Int. 2015;2015:549412.

47. Roncuzzi L, Pancotti F, Baldini N. Involvement of HIF-1alpha activation in the doxorubicin resistance of human osteosarcoma cells. Oncol Rep. 2014;32(1):389-394. 
OncoTargets and Therapy

\section{Publish your work in this journal}

OncoTargets and Therapy is an international, peer-reviewed, open access journal focusing on the pathological basis of all cancers, potential targets for therapy and treatment protocols employed to improve the management of cancer patients. The journal also focuses on the impact of management programs and new therapeutic agents and protocols on

patient perspectives such as quality of life, adherence and satisfaction The manuscript management system is completely online and includes a very quick and fair peer-review system, which is all easy to use. Visit http://www.dovepress.com/testimonials.php to read real quotes from published authors.

Submit your manuscript here: http://www.dovepress.com/oncotargets-and-therapy-journal 